\title{
PENGARUH PUPUK ORGANIK CAIR UNITAS SUPER ASAL Chromolaena odorata TERHADAP PERTUMBUHAN DAN HASIL PADI HITAM (Oryza sativa L.)
}

(Influence of Unitas Super From Chromolaena odorata as Liquid Organic Manure on Growth and Yield of Black Rice)

JAMILAH JAMILAH, BEBEN KURNIAWAN DAN ZAHANIS ZAHANIS

\author{
Program Studi Agroteknologi \\ Universitas Tamansiswa Padang \\ Jl. Tamansiswa No. 9 Padang, Sumatera Barat \\ Email: jamilahfatika@gmail.com; benkarim547@yahoo.com; zahanis@gmail.com
}

\begin{abstract}
The aim of this research was to know the influence of concentration and interval of Liquid organic manure (LOM) Unitas Super (US) from Chromolaena odorata on growth and yield of black rice (Oryza sativa L.). The experiment was conducted from October 2016 to March 2017 in Lubuk Minturun Urban Village, Koto Tangah Sub-district, Padang. The experiments were arranged in Completely Randomized Design, with 6 doses of POC Unitas Super (US) (V/v) with water, ie; $0 \mathrm{ml} \mathrm{L-1}$ (F1); $50 \mathrm{ml} \mathrm{L-1,} 1$ time a week (F2), $50 \mathrm{ml}$ L-1, 1 time 2 weeks (F3), $100 \mathrm{ml}$ L-1, a weekly (F4), 100 $\mathrm{ml} \mathrm{L-1,} 1$ time every 2 weeks (F5); $150 \mathrm{ml} \mathrm{L-1} \mathrm{POC} \mathrm{US,} 1$ time every 3 weeks (F6), and 3 replications. The data obtained were analyzed using analysis of variance (ANOVA) $5 \%$ real level. If the treatment had a significant effect, it was continued with LSD test of $5 \%$ real level. Parameters observed include; Plant height, the maximum number of tillers and productive, flowering age, harvest, panicle length, the number of grains per panicle, weight of 1000 seeds, the weight of dry grain per hectare, percentage of empty grain and harvest index. The experimental results proved that there was an influence of LOM Unitas Super treatments on maximum tillers, empty grain, panicle length and dry grain harvest, and some other parameters were not significance. The conclusion was the giving of $50 \mathrm{ml} L-1$ POC Unitas Super given every week is the best treatment. The highest rice yield reached 6.79 tons ha-1 dry milled grain, with harvest index reached 0.49 .
\end{abstract}

Keywords: Chromolaena odorata, liquid organic manure Unitas Super, black rice

\section{PENDAHULUAN}

Tanaman padi hitam (Oryza sativa L.) masih belum berkembang pesat di Sumatera Barat. Hal ini disebabkan petani masih belum terbiasa menanam padi hitam. Pada akhirakhir ini kebutuhan beras padi hitam meningkat. Suplier beras padi hitam lebih banyak memasok berasnya ke supermarket yang besar atau sekelas Mall. Menurut Chaudhary (2003) in Sompong et al., (2011) produsen beras hitam tertinggi adalah Cina (62\%), diikuti oleh Srilanka (8,6\%), Indonesia $(7,2 \%)$, India $(5,1)$, Pilipina (4,3\%), Bangladesh $(4,1 \%)$ dan beberapa negara lainnya yaitu Malaysia, Thailand dan Myanmar. Hao et al. (2015) melaporkan bahwa padi hitam memiliki beberapa keunggulan dibandingkan jenis padi tergolong beras putih antara lain; kaya serat sehingga menghasilkan energi secara bertahap, kadar gula lebih rendah, indek glikemik juga rendah, dan beberapa asam amino penting. Oleh sebab itu, beras hitam lebih banyak dikonsumsi bagi penderita diabetes.

Padi hitam adalah varietas yang memiliki warna ungu gelap biasa dibuddiaya di Asia (Kamiya et al., 2014a). Ada 9 jenis antosianin terkandung pada beras hitam, sedangkan aktivitas antioksidan padi hitam yang diekstrak terkandung sebanyak 41,69\% dari antosianin (Hao et al., 2015). Menurut Sompong et al. (2011) Cyanidin 3-glucoside dan peonoidin 3-glucoside dengan kisaran masing-masing sebesar 19.4 to $140.8 \mathrm{mg} / 100$ $\mathrm{g}$ bahan kering dan 11.1-12.8 mg/100 g bahan kering merupakan antosianin yang dominan pada tanaman padi hitam. Menurut Kamiya et 
al. (2014b) padi hitam dipengaruhi oleh kandungan pigmen antosianin yang ada pada padi tersebut. Antosianin tersebut merupakan anggota dari kelompok flavonoid dari fito kimia, yang dikenal berperan penting meningkatkan bioaktivitas pada hewan, termasuk memperbaiki pandangan, aktivitas antioksidasi, dan aktivitas anti kanker.

Pemberian POC Unitas Super (US)

yang berbahan baku tanaman semak Chromolaena odorata sudah dicobakan pada padi Varietas Pandan Wangi dan Cisokan baik di Dataran rendah maupun Dataran sedang (720 m dari permukaan laut). Jamilah et al., (2017); Jamilah dan Helmawati (2015); Jamilah et al., (2015); Jamilah dan Juniarti (2015) membuktikan bahwa POC US yang diberikan dengan konsentrasi $20 \%$ setiap 2 minggu sekali mampu meningkatkan pertumbuhan dan hasil padi ladang mapun padi sawah tersebut dibandingkan tanaman yang diaplikasikan oleh pupuk cair komersial. Tujuan adalah untuk mengetahui konsentrasi dan interval aplikasi POC US terhadap pertumbuhan dan hasil padi beras hitam Jileteng.

\section{BAHAN DAN METODE}

Penelitian ini telah dilaksanakan di lahan sawah Koto Panjang Ikua Koto.Kec. Koto Tangah di Kota Padang dari Oktober 2016 sampai Maret 2017 dengan jenis tanah Ultisol. Bahan yang dibutuhkan dalam percobaan ini adalah; POC US, benih Padi Hitam (Jileteng), pupuk yang diberikan $75 \%$ takaran rekomendasi. Takaran rekomendasi antara lain 200 kgha-1 Urea, 150 kgha-1 SP36, $100 \mathrm{~kg}$ ha-1 $\mathrm{KCl}$ sebagai pupuk dasar, waring, kayu tonggak. Alat yang dibutuhkan antara lain cangkul, ember, saringan, sprayer, parang, pisau, meteran, alat tulis, gunting tanaman dan lain - lain.

Percobaan ini dilakukan dengan menggunakan Rancangan Acak Lengkap (RAL) dengan 6 perlakuan yaitu; $0 \mathrm{ml} \mathrm{POC}$ US (F1); 50 ml L-1 POC US diberikan 1 kali seminggu (F2), $50 \mathrm{ml}$ L-1 POC US diberikan 1 kali 2 minggu (F3), $100 \mathrm{ml} \mathrm{L-1} \mathrm{POC} \mathrm{US}$ diberikan 1 kali seminggu (F4), $100 \mathrm{ml} \mathrm{L-1}$
POC US diberikan 1 kali 2 minggu (F5) dan $150 \mathrm{ml} \mathrm{L-1}$ POC US diberikan 1 kali 3 minggu (F6), ulangan sebanyak 3 kali, total plot 18 buah. Ukuran plot $2 \times 2 \mathrm{~m}$ dengan jarak tanam $25 \times 25 \mathrm{~cm}$, ditanam 2 anakan per titik tanam. Data disidik ragam menggunakan ANOVA taraf nyata $5 \%$, jika perlakuan berpengaruh nyata maka dilanjutkan dengan uji LSD taraf nyata $5 \%$.

Benih padi disemai pada persemaian setelah berumur 2 minggu dipersemaian maka dipindah tanamkan ke lapangan.Tanaman padi dipupuk 1 minggu setelah pindah tanam, dengan memberikan keseluruhan pupuk SP36 dan $\mathrm{KCl}$, sedangan Urea diberikan hanya $50 \%$ dari takaran rekomendasi dan sisanya setelah 30 hari kemudian. Air dipertahankan menggenangi tanaman hingga $5 \mathrm{~cm}$ dari permukaan tanah, setelah mencapai fase pengisian gabah, bertahap air dikurangi untuk mempercepat proses pematangan.

Pemberian perlakuan POC US dilakukan mulai 1 minggu padi setelah tanam sesuai perlakuan dan dihentikan saat tanaman sudah memasuki pengisian gabah. Parameter yang diamati antara lain; tinggi tanaman, jumlah anakan maksimum, anakan produktif, umur berbunga, umur panen, panjang malai, persentase gabah hampa, jumlah gabah per malai, bobot 1000 butir gabah, berat gabah kering giling dan indek panen. Penetapan persentase gabah hampa dilakukan sebagai berikut: jumlah gabah hampa per malai/(jumlah gabah per malai) x 100\%. Indeks panen dilakukan dengan mengambil sampel gabah dan jerami per rumpun kemudian dikering ovenkan pada suhu $70^{\circ} \mathrm{C}$ selama 3 hari atau hingga berat konstan. Kemudian dengan menggunakan rumus sebagai berikut: berat gabah kering tetap/(berat gabah kering tetap+ berat jerami kering tetap).

\section{HASIL DAN PEMBAHASAN}

Pengaruh konsentrasi dan interval pemberian POC US berpengaruh nyata terhadap anakan maksimum, dan sebaliknya tidak nyata terhadap tinggi tanaman, anakan produktif, umur berbunga dan panen padi hitam (Tabel 1). 
Tabel 1. Pengaruh kombinasi interval dan konsentrasi POC US terhadap komponen pertumbuhan vegetatif dan umur bunga serta panen tanaman padi hitam Jileteng

\begin{tabular}{|c|c|c|c|c|c|}
\hline $\begin{array}{l}\text { Perlakuan pemberian dan interval } \\
\text { POC US }\end{array}$ & $\begin{array}{l}\text { Tinggi } \\
\text { tanaman } \\
\text { (cm) }\end{array}$ & $\begin{array}{l}\text { Jumlah } \\
\text { Anakan } \\
\text { maksimum }\end{array}$ & $\begin{array}{l}\text { Jumlah } \\
\text { Anakan } \\
\text { produktif }\end{array}$ & $\begin{array}{l}\text { Umur } \\
\text { berbunga } \\
75 \% \text { (hari) }\end{array}$ & $\begin{array}{r}\text { Umur } \\
\text { panen } \\
\text { (hari) }\end{array}$ \\
\hline $\mathrm{F} 1\left(0 \mathrm{ml} \mathrm{L}^{-1}\right)$ & 112.67 & $26.17 \quad b$ & 18.83 & 73,00 & 101,00 \\
\hline F2 (50 $\mathrm{ml} \mathrm{L}^{-1}$ setiap 1 minggu) & 110.00 & $26.83 b$ & 21.33 & 72,00 & 100,00 \\
\hline F3 (50 ml L ${ }^{-1}$ setiap 2 minggu) & 113.33 & 25.50 & 19.67 & 72,00 & 100,00 \\
\hline F4 (100 $\mathrm{ml} \mathrm{L}^{-1}$ setiap 1 minggu) & 110.67 & 24.33 & 18.67 & 71,33 & 99,33 \\
\hline F5 (100 $\mathrm{ml} \mathrm{L}^{-1}$ setiap 2 minggu & 113.17 & 26.00 & 19.33 & 70,67 & 98,67 \\
\hline F6 (150 $\mathrm{ml} \mathrm{L}^{-1}$ setiap 3 minggu) & 111.80 & $31.00 \quad \mathrm{a}$ & 18.80 & 72,00 & 100,00 \\
\hline KK & 3,09 & 7,06 & 14,77 & 2,64 & 1,77 \\
\hline
\end{tabular}

Keterangan: Angka yang diikuti huruf kecil yang sama pada kolom yang sama berbeda tidak nyata menurut LSD taraf nyata $5 \%$

Secara umum tidak ada perbedaan masing-masing pemberian interval dan konsentrasi POC US terhadap tinggi tanaman, jumlah anakan produktif, umur berbunga dan umur panen padi hitam Jileteng. Hal ini membuktikan bahwa beberapa komponen pertumbuhan tersebut lebih dominan dipengaruhi fakor genetik dibandingkan efek lingkungan khususnya pemupukan organic cair. Namun demikian efek POC terlihat nyata terhadap jumlah anakan maksimum. Anakan maksimum tertinggi diperoleh pada perlakuan F6 (150 $\mathrm{ml} \mathrm{L}^{-1}$ setiap 3 minggu).

Anakan maksimum tertinggi diperoleh pada perlakuan F6, mencapai 31 anakan. Anakan maksimum belum bisa menjadi ketentuan untuk menghasilkan produksi gabah padi yang tinggi. Jika ditinjau jumlah anakan produktif terlihat bahwa anakan maksimum yang tinggi belum mampu menghasilkan anakan produktif yang tinggi juga. Jumlah anakan ini juga hampir sama terbentuk dibandingkan beras putih Pandan Wangi maupun Cisokan (Jamilah dan Helmawati, 2015). Jumlah anakan Jileteng berkisar 24 - 31 anakan lebih tinggi dibandingkan jumlah anakan padi hitam Toraja (Cristanti dan Arisoesilaningsih, 2013) yaitu sebanyak 16 20 anakan. Pada (Gambar 1) menampilkan perkembangan pertumbuhan dan jumlah anakan hingga berbunga tanaman padi berdasarkan usia tanaman.

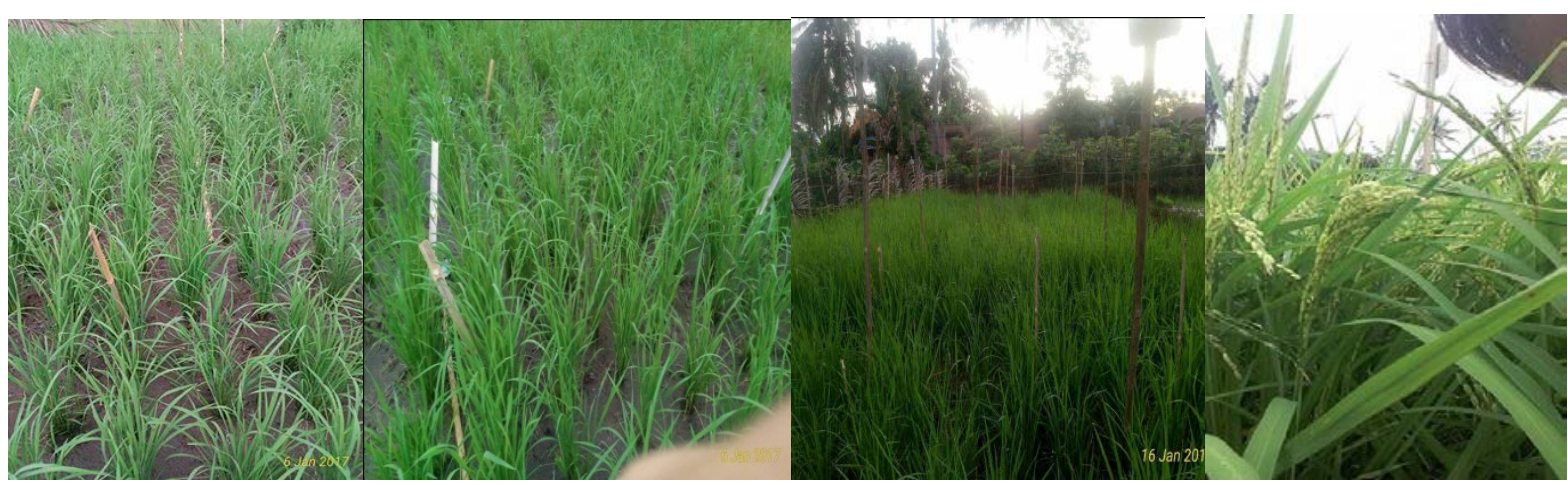

Gambar 1. Pertumbuhan tanaman padi mulai dari 2, 4, 6 minggu setelah tanam dan fase berbunga

Jumlah anakan produktif, umur berbunga dan umur panen tidak nyata dipengaruhi oleh perlakuan pemberian POC US. Anakan produktif cederung juga lebih banyak pada perlakuan $50 \mathrm{ml} \mathrm{L}^{-1}$ POC US yang diberikan 1 minggu sekali.Namun umur berbunga tidak menunjukkan lebih cepat dibandingkan perlakuan POC lainnya. Secara umum tanaman padi membutuhkan selama + 70 hst untuk mencapai berbunga $75 \%$ dan panen mencapai 98 - 101 hari. Hal ini menunjukkan tanaman padi hitam Jileteng tergolong usia genjah ( \pm 100 hari).
Hasil analisis statistik menunjukkan ada pengaruh pemberian POC tersebut terhadap beberapa komponen hasil tanaman padi Jileteng, antara lain; panjang malai, berat gabah kering panen, dan gabah hampa (\%). Hasil yang terbaik diperoleh dari percobaan pada perlakuan F2 (50 ml L-1 POC setiap 1 minggu), kemudian diikuti oleh perlakuan F4 (100 $\mathrm{ml} \mathrm{L-1}$ setiap 1 mingu) disajikan pada (Tabel 2) dan (Gambar 2, dan 3). Tanaman yang tidak diberi POC secara umum pertumbuhannya paling jelek. Hal ini membuktikan bahwa POC sangat dibutuhkan untuk pertumbuhan tanaman padi hitam. Tabel 2. ini memberikan informasi bahwa 
penting sekali memberikan POC berdasarkan interval pemberian dibandingkan konsentrasi yang akan diberikan. Jika konsentrasi tinggi diberikan hingga $150 \mathrm{ml} \mathrm{L}^{-1}$, yang diberikan tiap 3 minggu sekali, tidak akan meningkatkan pertumbuhan maupun hasil padi dibandingkan dengan pemberian dalam konsentrasi rendah akan tetapi diberikan lebih sering, atau interval lebih sering. Gabah hampa akan menurun jumlahnya jika interval pemberian POC diberikan setiap minggu, dan meningkat kehampaan gabah kalau interval makin jarang yaitu 2 hingga 3 minggu. Seiring dengan kehampaannya sangat rendah maka hasil gabah yang diperoleh menjadi meningkat dan mencapai hasil yang tertinggi dibandingkan dengan perlakuan lainnya.

Tabel 2. Pengaruh kombinasi interval dan konsentrasi Pupuk Organik Cair terhadap komponen hasil tanaman padi hitam Jileteng

\begin{tabular}{|c|c|c|c|c|c|c|c|c|c|}
\hline $\begin{array}{l}\text { Perlakuan pemberian } \\
\text { dan interval POC }\end{array}$ & $\begin{array}{l}\text { Panja } \\
\text { malai }\end{array}$ & & $\begin{array}{l}\text { Jumlah } \\
\text { gabah per } \\
\text { malai }\end{array}$ & $\begin{array}{l}\text { Berat } 1000 \\
\text { butir } \\
\text { (g) }\end{array}$ & $\begin{array}{l}\text { Bera } \\
\text { (tont }\end{array}$ & $\begin{array}{l}\mathrm{GKG} \\
-1)\end{array}$ & $\begin{array}{l}\text { Indek } \\
\text { Panen }\end{array}$ & $\begin{array}{l}\text { Gabah } \\
\text { hampa }\end{array}$ & \\
\hline F1( tanpa POC) & 25.33 & $\mathrm{C}$ & 143.83 & 30.90 & 4,36 & C & 0.43 & 14.20 & bc \\
\hline $\mathrm{F} 2\left(50 \mathrm{ml} \mathrm{L}^{-1^{\prime}}\right.$ setiap 1 & & & & & & & & & \\
\hline $\begin{array}{l}\text { minggu) } \\
\text { F3 (50 } \mathrm{ml} \mathrm{L}^{-1} \text { setiap } 2\end{array}$ & 27.83 & b & 137.50 & 31.09 & 6,79 & $\mathrm{a}$ & 0.49 & 9.66 & $\mathrm{a}$ \\
\hline $\begin{array}{l}\text { minggu }) \\
\mathrm{F} 4\left(100 \mathrm{ml} \mathrm{L}^{-1} \text { setiap } 1\right.\end{array}$ & 29.50 & $a b$ & 166.17 & 29.29 & 5,40 & $\mathrm{~b}$ & 0.48 & 13.04 & bc \\
\hline $\begin{array}{l}\text { minggu) } \\
\mathrm{F} 5\left(100 \mathrm{ml} \mathrm{L}^{-1} \text { setiap } 2\right.\end{array}$ & 31.00 & $\mathrm{a}$ & 154.83 & 31.39 & 5,67 & $\mathrm{~b}$ & 0.48 & 10.51 & $\mathrm{a}$ \\
\hline $\begin{array}{l}\text { minggu } \\
\text { F6 }\left(150 \mathrm{ml} \mathrm{L}^{-1} \text { setiap } 3\right.\end{array}$ & 27.83 & $\mathrm{~b}$ & 168.50 & 30.88 & 4,92 & bc & 0.47 & 11.07 & $a b$ \\
\hline minggu) & 26.80 & bc & 160.80 & 31.61 & 4,63 & c & 0.46 & 16.30 & C \\
\hline $\mathrm{KK}(\%)$ & 3,73 & & 12,08 & 8,61 & 15,77 & & 13,90 & 19,45 & \\
\hline
\end{tabular}

Keterangan: Angka yang diikuti huruf kecil yang sama pada kolom yang sama berbeda tidak nyata menurut LSD taraf nyata 5\%

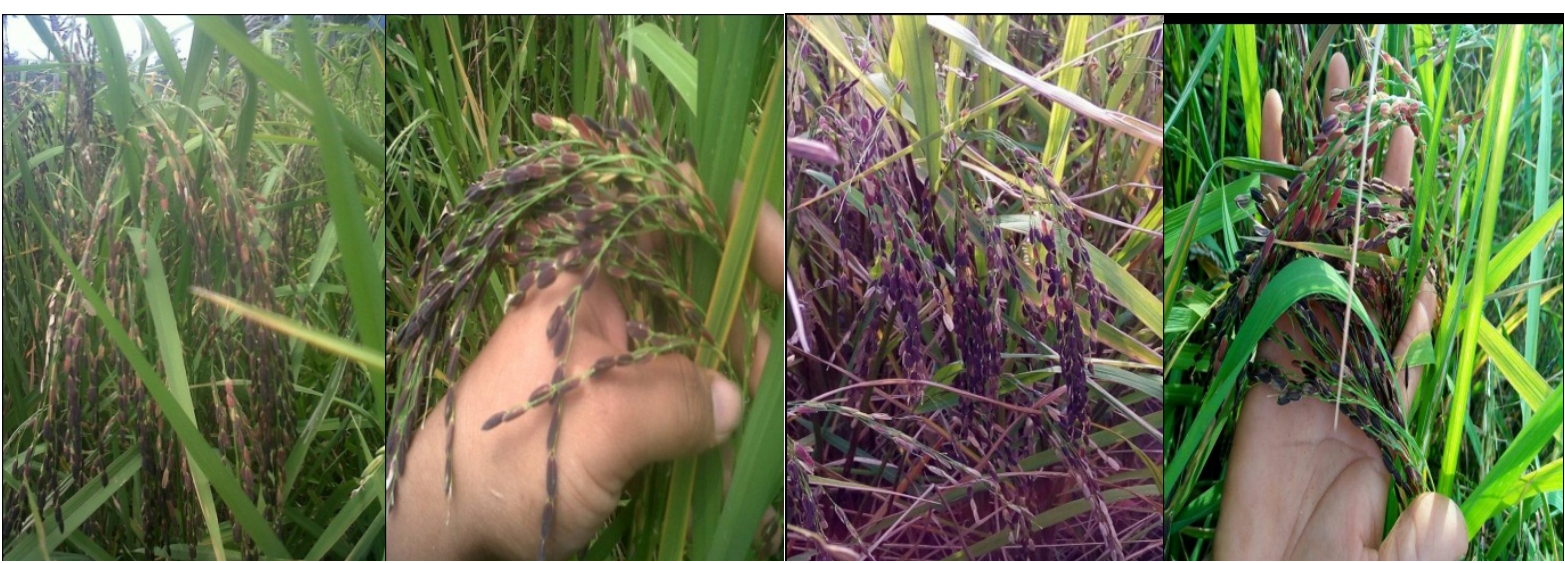

Gambar 2. Fase pembentukan malai dan pengisian pada padi hitam Jileteng

Kehampaan sangat ditentukan antara lain; oleh ketersediaan unsur hara yang dapat diserap oleh tanaman baik melalui tanah maupun dari daun sebagai foliar apllication. Seperti yang sudah dijelaskan oleh
(Gamboa.G et al., 2016); (Legaz \& Qui, 2016) bahwa serapan unsur hara $\mathrm{N}$ pada daun tinggi bila tanaman menerima unsur $\mathrm{N}$ dalam bentuk $\mathrm{NH}_{4}^{+}$dan $\mathrm{NO}^{-}$secara bersamaan.

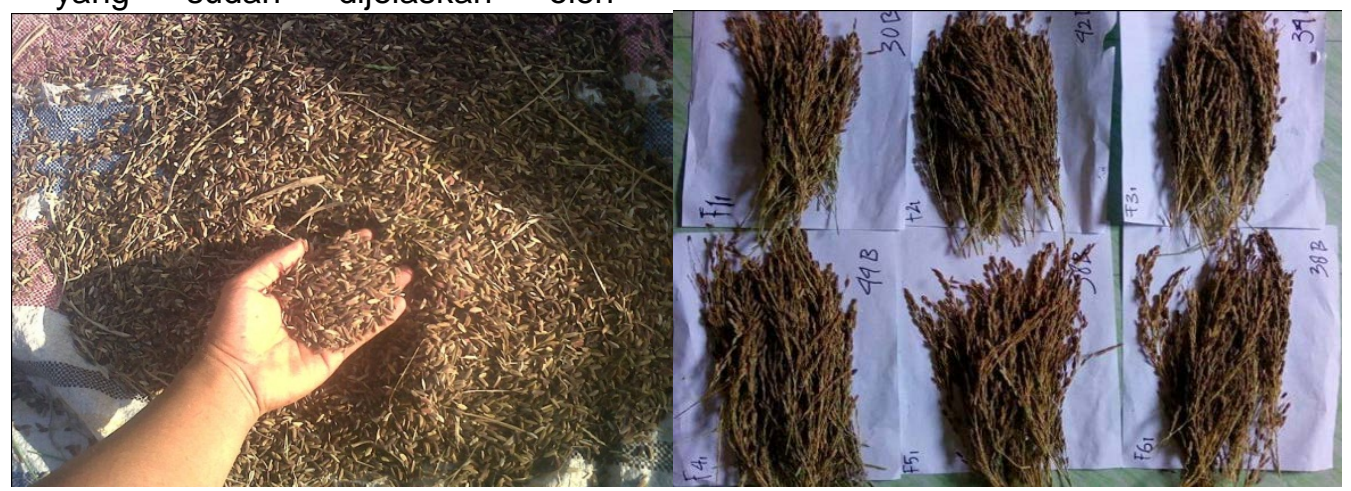


Gambar 3. Produksi gabah padi hitam yang dipengaruhi oleh berbagai perlakuan mulai dari F1, F2, F3, F4, F5 dan F6.

Jumlah gabah padi permalai tidak dipengaruh secara nyata oleh pemberian POC US, dan jumlah gabah yang terbentuk berkisar 137168 bulir. Jumlah bulir ini hampir sama dengan jumlah gabah padi varietas Melik, Cempo Melik dan Wulung yang tergolong beras hitam juga (Samyuni dkk., 2015). Demikian pula bobot 1000 butir gabah tidak dipengaruhi oleh perlakuan pemberian POC US. Hasil bobot tersebut sangat dipengaruhi oleh faktor genetis dibandingkan dengan faktor lingkungan. Jika faktor lingkungan sangat baik sesuai dengan kebutuhan hidup tanaman, maka bobot 1000 butir akan dipengaruhi oleh faktor genetik.

$$
\text { Pemberian } 50 \mathrm{ml} \mathrm{L}^{-1} \text { setiap } 2 \text { minggu }
$$
sekali dan $100 \mathrm{ml} \mathrm{L}^{-1}$ setiap 2 minggu sekali tidak menunjukkan perbedaan nyata terhadap hasil gabah kering giling padi hitam. Hal ini membuktikan bahwa pada aplikasi POC, konsentrasi bukan menjadi hal terpenting kelihatannya, akan tetapi interval waktu yang sangat menentukan. Jika dilihat perlakuan pemberian $50 \mathrm{ml} \mathrm{L}^{-1}$ diberikan setiap minggu dan $100 \mathrm{ml} \mathrm{L}^{-1}$ diberikan setiap minggu, menunjukkan perbedaan yang tidak nyata. Hal ini membuktikan juga sekali lagi bahwa konsentrasi tinggi bukan menjadi penentu dalam meningkatkan pertumbuhan dan hasil padi, akan tetapi lebih kepada interval pemberiannya walaupun diberikan dalam dosis yang rendah.Hal ini sudah dijelaskan oleh (Mengel et al., 2001) bahwa unsur hara yang diserap tanaman melalui daun lebih rendah dibandingkan dengan yang dibutuhkannya. Menurut (Jamilah \& Juniarti, 2015) kandungan hara lengkap dijumpai dalam POC US, antara lain; 3,64\% N; $1,48 \% \mathrm{P} ; 1,66 \% \mathrm{~K}$; pH sebesar 7,96 . Beberapa unsur mikro juga terkandung di dalamnya antara lain; $\mathrm{Fe}, \mathrm{Zn}, \mathrm{Cu}$, Mo dan lainlain. Kandungan hara tersebut sesuai dengan ketentuan dari (Nasional, 2013).

Efek konsentrasi POC yang diberikan terhadap tanaman padi, tidak menjadi penentu. Hal terpenting sebagai penentu respon tanaman padi adalah kemampuan tanaman tersebut dalam menerima unsur hara yang diberikan melalui daun. Karena kemampuan unsur hara berdifusi sangat ditentukan oleh kondisi metabolisme tanaman, jika diberikan konsentrasi tinggi, namun kemampuan difusi sangat dibatasi oleh tanaman tersebut.Jika diamati dari (Tabel 2.) tersebut membuktikan bahwa pentingnya memberikan POC setiap minggu walaupun konsentrasi diberikan rendah. Karena interval setiap minggu mampu menyediakan unsur hara selama pertumbuhan tanaman tersebut dan sangat tepat saat tanaman membutuhkannya.
Hal ini disebabkan metaboslime tanaman berlangsung setiap hari. Kebutuhan unsur hara tanaman sepanjang usia tanaman tersebut khususnya selama pertumbuhan fase vegetatif aktif.

Indek panen merupakan penetapan yang dilakukan terhadap produksi gabah kering dibandingkan dengan produksi total gabah dan jerami kering. Jika semakin tinggi angka indek panen menunjukkan komponen hasil lebih tinggi dibandingkan dengan komponen jerami.Pada percobaan ini perlakuan pemberian $\mathrm{POC}$ US tidak memberikan pengaruh yang nyata terhadap indek panen padi hitam. Namun angka tertinggi masih berada pada perlakuan pemberian 50 $\mathrm{ml} \mathrm{L}^{-1}$ POC US yang diberikan tiap minggu.

\section{KESIMPULAN DAN SARAN}

Pemberian $50 \mathrm{ml}$ L-1 pupuk Organik Cair Unitas Super yang diberikan setiap minggu mulai 2 minggu pindah tanam hingga berbunga mampu meningkatkan pertumbuhan dan hasil padi hitam Jileteng. Hasil padi tertinggi mencapai 6,79 ton ha-1 gabah kering giling, dengan indek panen mencapai 0,49.

\section{Ucapan Terima Kasih}

Ucapan terima kasih disampaikan kepada Kemenristek Dikti, karena telah mendanai sebagian kegiatan ini melalui skim Hibah Strategis Nasional nomor kontrak; 01/KONTRAK-PENELITIAN/010/KM/2016, tanggal 22 Februari 2016.

\section{DAFTAR PUSTAKA}

Cristanti, L. D., \& Arisoesilaningsih, E. (2013). Pertumbuhan Padi Hitam Dan Serangan Beberapa Herbivor Di Sawah Padi Organik Kecamatan Kepanjen. Jurnal Biotropika, 1(5): 221-225.

Gutiérrez-Gamboa, G., Garde-Cerdán, T., Gonzalo-Diago, A., \& Martínez-Gil, A. M. (2016). Effect Of Different Foliar Nitrogen Applications On The Must Amino Acids And Glutathione Composition In Cabernet Sauvignon Vineyard. LWT - Food Science And Technology. Http://Doi.Org/ 101016/J.Lwt. 2016.08.039

Hao, J., Zhu, H., Zhang, Z., Yang, S., \& Li, H. (2015). Identification Of Anthocyanins In Black Rice (Oryza Sativa L.) By UPLC I Q- TOF-MS And Their In Vitro And In 
Vivo Antioxidant Activities. Journal of Cereal Science, 64, 92-99. Http://Doi.Org/10.

1016/J.Jcs.2015.05.003

Jamilah, Ediwirman, \& Ernita, M. (2015). The Effect Of Fermented Liquid Organic FerTilizer And Potassium For Nutrient Uptake And Yield Of Rice At Tropical Upland. J. Environ.Res.Develop., 9(4): $1-6$.

Jamilah, Fadhila, R., \& Mulyani, S. (2017). Farm Analysis Of Rice Crop Trimmed Periodically In The Tropical Wet. In T. Yuwono, T. Purwaningsih, \& Maulana (Eds.), International Conference On Social, Humanities And Government Science ISBN 978-602607620-5 (Pp. 202-207). Palembang: Tamansiswa Palembang University.

Jamilah, \& Helmawati. (2015). Kajian Analisis Usaha Tani Integrasi Padi Sawah Dan Pakan Ternak Ruminansia Menunjang Kedaulatan Pangan Dan Daging Dalam Menghadapi Masyarakat Ekonomi Asean 2015. In Seminar Nasional Kesiapan Indonesia Dalam Menghadapi Pasar Bebas Asean Melalui Penguatan Implementasi Corporate Governance Yang Sehat (Vol. 3, Pp. 254-266). Padang: Perpustakaan Nasional RI.

Jamilah, \& Juniarti. (2015). Potensi Tanaman Padi Dipangkas Secara Periodikuntuk Pakan Ternak Pada Metoda Budidaya Integrasi Padi Ternak Menunjang Kedaulatan Pangan Dan Daging: Laporan Penelitian Fakultas Pertanian Univ. Tamansiswa, Padang (Vol. 53). Padang.

Kamiya, H., Yanase, E., \& Nakatsuka, S. (2014a). Novel Oxidation Products of
Cyanidin 3- O -Glucoside With 2 , Content And Its Oxidation In Black Rice. FOOD CHEMISTRY, 155, 221-226. http://doi. org/10.1016/j.foodchem. 2014.01.077

Kamiya, H., Yanase, E., \& Nakatsuka, S. I. (2014b). Novel Oxidation Products Of Cyanidin 3-O-Glucoside With 2,2 Azobis-(2,4-Dimethyl)Valeronitrile and Evaluation of Anthocyanin Content and Its Oxidation in Black Rice. Food Chemistry, 155, 221-226.http://doi.org/ 10.1016/j.foodchem.2014.01.077

Legaz, F., \& Qui, A. (2016). Liquid Organic Fertilizers for Sustainable Agriculture: Nutrient Uptake of Organic versus Mineral Fertilizers in Citrus Trees, 1-20. http://doi.org/10.1371/journal.pone.0161 619

Mengel, K., Kirkby, E. a., Kosegarten, H., \& Appel, T. (2001). Principles of Plant Nutrition Edited by and, 5th, $849 \mathrm{pp}$. http://doi.org/10.1007/978-94-010-10092

Nasional, B. S. (2013). Standar Nasional Indonesia (SNI) 6729:2013 Sistem pertanian organik. Samyuni, Purwanto, E., \& Supriyadi. (2015). Toleransi Varietas Padi Hitam (Oryza sativa L. indica) Pada Berbagai Tingkat Cekaman Kekeringan. El-Vivo, 3(2): 54-63.

Sompong, R., Siebenhandl-ehn, S., Linsberger-martin, G., \& Berghofer, E. (2011). Physicochemical And Antioxidative Properties Of Red And Black Rice Varieties From Thailand, China And Sri Lanka. Food Chemistry, 124(1),132-140.http://doi.org/10.1016/j. food chem.2010.05.115 